\title{
SEKOLAH ALAM: EVALUASI PROGRAM SEKOLAH DALAM MENUMBUHKAN KECERDASAN NATURALISTIK DAN KINESTETIK PADA PENDIDIKAN ANAK USIA DINI
}

\author{
Taufiq Satria Mukti, Mutiara Arlisyah Putri Utami, \\ dan Fantika Febry Puspitasari \\ Universitas Islam Negeri Maulana Malik Ibrahim
}

\begin{abstract}
Naturalist and kinestetic Intelligence in Early childhood become the main parameters in the stages of growth and development. This Intelligence becomes a strong foundation in the future in achieving self-success in the industrial era 4.0. In guarding the growth and development of early childhood, Sekolah Alam was an solutions to prpare for the golden generation in the future. Program evaluation carried out with the CIPP (Context Input Process Poduct) model approach aim to measures the achievement of the implementation of the organizing and outcome program for the students. The result showed that the implementation of the program was in the very good category $88,9 \%$ and outcome $87,5 \%$ student achievied the curriculum target, so it can be concluded that the Sekolah Alam curriculum was succesfully implemented to build the naturalist and kinesthetic intelligence.
\end{abstract}

Keywords Sekolah Alam, Program Evaluation, Naturalist Intelligence, and Kinesthetic Intelligence.

Abstrak: Kecerdasan naturalis dan kinestetik pada anak usia dini menjadi parameter utama dalam tahap pertumbuhan dan perkembangan. Kecerdasan ini menjadi fondasi yang kuat di masa depan dalam mencapai kesuksesan diri di era industri 4.0. Dalam mengawal pertumbuhan dan perkembangan anak usia dini, Sekolah Alam adalah solusi untuk mempersiapkan generasi emas di masa depan. Evaluasi program yang dilaksanakan dengan pendekatan model CIPP bertujuan untuk mengukur pencapaian implementasi program lembaga penyelenggara dan outcome pada peserta didik. Hasil menunjukkan bahwa implementasi program berada dalam sangat kategori baik $88,9 \%$ dan outcome peserta didik 87,5\% mencapai target kurikulum, sehingga dapat disimpulkan bahwa kurikulum Sekolah Alam berhasil dilaksanakan.

Kata Kunci: Sekolah Alam, Evaluasi Program, Kecerdasan Naturalis, dan Kecerdasan Kinestetik

\section{A. PENDAHULUAN}

Kecerdasan berperan penting bagi kelangsungan hidup. Kecerdasan yang ada pada diri manusia sangat beragam dan berbeda-beda (Fitriani, 2018). Kecerdasan yang manusia miliki merupakan tolak ukur pencapaian individu yang dapat dieksplorasi, 
ditumbuhkan, serta dikembangkan secara optimal melalui berbagai macam teknik dan stimulasi yang tepat sesuai tahap perkembangannya.

Kecerdasan yang ada pada tiap individu tidak hanya satu, atau dikenal dengan istilah Multiple Intelligence. (Gardner, 2011) menyatakan bahwa kecerdasan majemuk meliputi kecerdasan Linguistic, kecerdasan logika matematika, kecerdasan spasial, kecerdasan kinestetik, kecerdasan musical, kecerdasan interpersonal, kecerdasan intrapersonal, kecerdasan naturalis, kecerdasan eksistens. Kecerdasan yang perlu di optimalkan pada masa pertumbuhan dan perkembangan adalah kecerdasan kinestetik dan naturalis.

Kecerdasan kinestetik berkaitan erat dengan perkembangan motorik anak. Kecerdasan kinestetik pada anak akan berkembang dengan baik jika dididik dan dilakukan pelatihan (Yuningsih, 2015). Perkembangan motorik akan berpengaruh terhadap kekuatan fisik (Hasanah, 2016), sehingga di masa selanjutnya anak dengan fisik yang kuat akan mampu merealisasikan gerakan atau tindakan sesuai dengan apa yang ada di pikiran.

Stimulus yang diberikan dengan baik akan mendorong perkembangan kecerdasan kinestetik anak. Stimulus dapat berupa gerak seluruh anggota tubuh yang terkoordinasi dengan baik. Gerak seluruh anggota tubuh ini sebagai bentuk mengekspresikan ide atau gagasan dan emosi melalui sebuah gerakan dalam membuat atau melakukan sesuatu. Kecerdasan kinestetik ini meliputi koordinasi, keseimbangan, ketrampilan, kekuatan, kelenturan, kecepatan dan keakuratan menerima rangsangan, sentuhan, dan tekstur (Armstrong, 2009). Kecerdasan gerak kinestetik pada manusia tersentral pada otak cereblum (otak kecil), bangsal ganglia (otak keseimbangan), dan motor korteks.

Dasar dari pentingnya pengoptimalan kecerdasan kinestetik untuk anak usia dini meliputi (1) anak memiliki tubuh yang lebih lentur dari orang dewasa; (2) anak belum mempunyai banyak ketrampilan yang berbenturan dengan ketrampilan yang baru dipelajarinya; (3) anak lebih suka mencoba sesuatu yang baru ketika masih kecil dari pada setelah dewasa; (4) anak sedang dalam tahap suka melakukan kegiatan secara berulang-ulang sehingga otot lebih terlatih untuk melakukan secara efektif; (5) tanggung jawab dan kewajiban yang dimiliki anak lebih kecil daripada ketika dewasa sehingga waktu anak untuk melatih keterampilan menjadi lebih banyak (Gardner, 2011).

Pada umumnya orang tua kurang memperhatikan kebutuhan pertumbuhan dan perkembangan di usia yang tepat sesuai tahapannya. Orang tua lebih mementingkan anak mempunyai kecerdasan akademik lain layaknya tuntutan orang dewasa. Begitu pula kecerdasan kinestetik pada pendidikan anak usia dini yang kurang mendapat perhatian sehingga perkembangan yang berlangsung tidak optimal. Pengoptimalan pertumbuhan dan perkembangan kecerdasan tersebut perlu adanya stimulasi. Stimulasi bagi kecerdasan kinestetik seharusnya adalah ruang terbuka yang memungkinkan mobilitas tinggi bagi anak. Akan tetapi hal ini menjadi kendala dan hambatan yang serius karena tidak tercukupinya ruang gerak untuk berekspresi. Sedangkan dari sudut pandang lain faktor utama yang sangat mempengaruhi adalah penerapan model 
pembelajaran pendidikan anak usia dini mayoritas masih dilaksanakan secara konvensional.

Kecerdasan lain yang mayoritas kurang mendapat perhatian adalah kecerdasan naturalis. Kecerdasan naturalis mencakup pengetahuan dan ilmu yang terkait dengan makhluk hidup beserta lingkungan yang ada di sekitarnya. Kecerdasan naturalis dikenalkan oleh Howard Gardner dengan menggambarkan dan menggolongkan jenis mereka (makhluk hidup) terhadap lingkungan alam. Kecerdasan Naturalis dalam aplikasinya banyak dimanfaatkan manusia untuk hidup dan berkehidupan. Seperi memanfaatkan tumbuhan sebagai bahan konsumsi, mengetahui waktu yang tepat untuk menyemai bibit, dan mengetahui teknik dalam melakukan pengobatan alami.

Kenyataan yang ada banyak pendidikan anak usia dini yang kurang mendukung untuk mengembangkan kecerdasan naturalis. Kurangnya sarana prasarana sekolah menjadi faktor utama, terlebih di kota besar jarang ditemui ekosistem alami dengan komponen pembentuk ekosistem seutuhnya. Kondisi ini akan berpengaruh terhadap tumbuh dan kembang anak, contoh sederhana adalah rasa malu yang besar pada anak untuk berinteraksi dengan lingkungan tempat tinggal.

Lingkungan alam merupakan literatur yang penting untuk menumbuh kembangkan kemampuan dan kecerdasan anak. Menghabiskan waktu di ruang-ruang alami bagi anak dapat meningkatkan kebugaran dan kemampuan seseorang untuk berkonsentrasi (Taylor \& Kuo, 2006). Ini juga telah dibuktikan untuk mengenali diri, perasaan tenang, pengembangan sensorik, kemampuan kognitif dan kreativitas. Oleh karena itu desain lingkungan memiliki peran penting dalam perkembangan mereka. Dengan lingkungan pendidikan yang natural anak-anak mampu menghabiskan banyak waktu di masanya sesuai kebutuhan pertumbuhan dan perkembangannya .

Penegasan pendapat tersebut juga dinyatakan oleh (Taylor \& Kuo, 2006) bahwa sejak usia dini kecerdasan naturalis sangat dibutuhkan bagi setiap orang. Kecerdasan ini berperan penting dalam menjaga dan memelihara naluri setiap manusia untuk dapat hidup dengan nyaman dalam tananan kehidupan yang seutuhnya. Dengan pernyataan tersebut menjadi penting bahwa pengembangan kecerdasan naturalis tidak terlepas dengan keberadaan alam. Alam berperan sebagai literatur terbaik bagi anak usia dini dalam melaksanakan pembelajaran yang menarik dan menyenangkan. Dengan demikian, pemanfaatan alam sebagai metode pendekatan pelaksanaan sekolah dalam menumbuhkan dan mengembangkan kecerdasan naturalis sangat diperlukan sehingga pada kenyataannya pengembangan kecerdasan naturalis dan kinestetik berkembang dengan optimal.

Untuk mewujudkan proses pendidikan yang demikian menjadi tugas bagi seluruh pelaku pendidikan agar mampu menerapkan pembelajaran yang menunjang perkembangan kecerdasan kinestetik dan naturalis sehingga anak mampu berinteraksi dan memahami dengan lingkungannya disekitarnya. Pembelajaran yang digunakan untuk mengembangkan kecerdasan naturalis ini seharusnya dilakukan di luar ruangan agar anak secara bebas dapat bereksplorasi (Daniati, 2019). 
Taylor \& Kuo (2006) berpendapat bahwa desain lingkungan ini memiliki peran penting dalam perkembangan mereka. Pembelajaran anak usia dini pada dasarnya menerapkan esensi bermain. Melalui bermain anak mampu bergerak secara leluasa untuk berinteraksi langsung dengan lingkungan sekitar. Kecerdasan kinestetik yang tinggi pada anak biasanya tampak bahwa anak suka menggunakan otot untuk mengeksplorasi lingkungan sekitar. Sedangkan anak yang memiliki kecerdasan naturalis yang tinggi akan merasa senang bereksplorasi dengan lingkungan alam dan sekitarnya. Adanya kecerdasan yang dimiliki tersebut anak mampu belajar sesuai tingkat kenyamanan yang proporsional, tingkat kepercayaan diri, dan akan sangat berpotensi dalam menumbuh kembangkan kreativitas. Anak akan lebih banyak terlibat dalam interaksi yang positif, terampil dalam menyelesaikan permasalahan, dan serta mampu mengekspresikan diri (Davis dkk., 2010). Melalui lembaga pendidikan anak akan mendapatkan stimulasi yang optimal serta didukung peran orang tua dalam mengoptimalkan kecerdasan yang dimiliki anak.

Pentingnya kecerdasan naturalis dapat menjadi dasar kuat terhadap menanamkan rasa kepekaan dan kesadaran terhadap lingkungan tempat tinggal sekaligus menjaga dan melestarikannya. Hal itulah yang akhir-akhir ini menjadi persoalan memperhatinkan bagi keberlangsungan hidup akibat dampak penebangan hutan liar, pemburuan hewan dan melakukan pembakaran hutan, maupun membuang sampah tidak pada tempatnya yang akhirnya menyebabkan berbagai macam ganggungan lingkungan yang bencana alam.

Era 4.0 adalah tantangan nyata bagi pendidikan Indonesia, khususnya pendidikan pada anak usia dini (Widaningsih dkk., 2019). Perlunya outcame peserta didik yang mempunyai bekal yang cukup untuk meneruskan pertumbuhan dan perkembangn pada tahap selanjutnya adalah menjadi fokus pengembangan pelaksanaan program belajar pada anak usia dini. Harapan dengan adanya inovasi pelaksanaan program pendidikan anak usia dini yang tidak hanya dilaksanakan secara konvensional akan lebih menguatkan kecerdasan anak usia dini yang lebih menitik beratkan pada kebutuhan pertumbuhan dan perkembangan anak usia dini yang fundamental.

Saat ini pendidikan anak usia dini di Indonesia semakin memiliki banyak inovasi. Salah satu inovasinya adalah sekolah berbasis alam. Sekolah berbasis alam ini bertujuan untuk mengoptimalkan pertumbuhan dan perkembangan kecerdasan naturalis dan kinestetik pada anak (Daniati, 2019). Proses pembelajaran yang diterapkan tentu tidak secara konvensional yang hanya dilakukan di dalam ruang kelas saja, akan tetapi pelaksanaan pendidikan dan pembelajaran yang dilakukan lebih sering di luar ruangan dan memanfaatkan ruang terbuka (alami) sehingga anak mampu berinteraksi langsung dengan makhluk hidup yang ada di sekitarnya. Tidak hanya itu, akan tetapi Sekolah Alam diharapkan mampu mendidik dan menanamkan kepribadian kuat pada anak.

Lingkungan alami yang dimaksud tidak serta merta pada konteks lingkungan alami yang sebenarnya, namun beberapa diantaranya perlu pengelolaan dan tatanan sehingga mampu menciptakan lingkungan yang terkondisi (Hashim \& Denan, 2015). Lingkungan yang terkondisi ini harus memenuhi aspek komponen ekosistem yang baik 
untuk menjadi literatur bagi proses pendidikan dan pembelajaran anak pada Sekolah Alam. Pembelajaran berbasis alam menjadi salah satu strategi dalam mengembangkan prinsip belajar yang menyenangkan, hal itu dikarenakan pembelajaran yang dilaksanakan berprinsip pada bermain sambil belajar dan menjadikan anak sebagai pusat pembelajaran (Spalie dkk., 2011). Pembelajaran berbasis alam ini dapat mengoptimalkan kecerdasan yang dimiliki oleh anak untuk beradaptasi secara kreatif dengan lingkungan alam. Lingkungan yang asri, aman, sejuk membuat anak nyaman untuk belajar.

Di Yogyakarta dapat ditemui beberapa Sekolah Alam. Sekolah berbasis alam yang diselenggarakan saat ini belum pernah dilakukan evaluasi. Perlunya penelitian evaluasi dilakukan adalah untuk memperoleh penilaian terhadap keterlaksanaan program. Berdasarkan berbagai pertimbangan yang telah di uraikan tersebut penelitian evaluasi dengan model CIPP (context, input, process, products) (Stufflebeam, 2002) akan diterapkan guna memperoleh informasi dari seluruh komponen penyelenggaraan Sekolah Alam. Pada penelitian evaluasi ini mempunyai juga tujuan untuk memperoleh informasi yang mendalam baik dari segi konteks atau kurikulum Sekolah Alam, proses pelaksanaan Sekolah Alam, serta produk atau outcame dari proses pendidikan yang berupa kepribadian, kecerdasan naturalis dan kecerdasan kinestetik. Dengan demikian secara keseluruhan pelaksanaan evaluasi dapat memberikan suatu rekomendasi perbaikan serta memberikan penilaian terhadap pelaksanaan program Sekolah Alam yang sudah berlangsung.

\section{B. METODE}

Evaluasi dilakukan dengan modifikasi model CIPP (context, input, process, dan product) (Stufflebeam, 2002). Modifikasi model berupa input, process, dan outcame . Cakupan input dalam Evaluasi yang akan di lakukan terdiri dari kurikulum, sarana dan prasarana, kompetensi pendidik, dan pembiayaan. Pada pelaksanaan Sekolah Alam meliputi Cakupan process yang terdiri dari pengelolaan, kegiatan pembeljaran/KBM, dan penilaian. Menurut teori model evaluasi oleh (Stufflebeam, 2002) menjelaskan bahwa Products yang dimaksud dapat berupa luaran yang berupa products itu sendiri atau outame yang telah berproses sehingga dapat di artikan sebagai hasil pencapaian belajar siswa di Sekolah Alam.

Subyek penelitian evaluasi adalah kepala sekolah, guru, dan maintenance (pemelihara sarana prasarana Sekolah Alam) di tiga TK Sekolah Alam yang ada di Yogyakarta, yaitu: TKIT Alam Nurul Islam Kecamatan Gamping, Kabupaten Sleman, KB Jogja Green School Kecamatan Gamping, Kabupaten Sleman, dan TK Alam Avicienna Kecamatan Banguntapan, Kabupaten Bantul. Secara garis besar Instrumen yang digunakan untuk mengumpulkan data terdiri dari instrumen kualitas kurikulum, instrumen kualitas proses penyelenggaraan, dan instrumen outcame atau lulusan. Instrumen meliputi angket dengan subjek peserta didik, maintenance, ataupun pendidik. Maka subjek peserta didik perlu treatment bahwa tersebut diisi oleh guru melalui observasi langsung terhadap peserta didik. Teknik ini dilakukan atas dasar subjek 
peserta didik belum mampu untuk mengisikan angket tersebut. Selain angket teknik observasi, wawancara dan dokumentasi terhadap seluruh komponen Sekolah Alam dilakukan dalam mengumpulkan data, sehingga harapannya informasi yang yang lebih detail dan mendalam. Ketepatan dan kebermaknaan instrumen diperoleh dengan melakukan analisis expert judgment atau pakar. Sedangkan keandalan instrumen diperoleh dengan analisis data uji coba menggunakan Conbach Alpha dengan bantuan program SPSS 16.

Analisis data terhadap capaian pelaksanaan program Sekolah Alam dilakukan dengan menggunakan teknik deskriptif kuantitatif. Capaian program di ukur dari input sekaligus proses dan outcame . Hal ini di dasarkan bahwa capaian outcame adalah hasil dari input dan proses uang salin terintegrasi.

Tabel 1. Analisis Data

\begin{tabular}{lllll}
\hline \multicolumn{2}{c}{ Teknik Analisis } & \multicolumn{3}{c}{ Tujuan } \\
\hline Cronbach Alpha dengan program SPSS 16 & $\begin{array}{l}\text { Uji reliabilitas instrumen yang diperoleh } \\
\text { dari uji coba dan pelaksanaan evaluasi }\end{array}$ \\
\hline $\begin{array}{l}\text { Confirmatory Factor Analysis } \\
\text { dengan program Lisrel }\end{array}$ & (CFA) & $\begin{array}{l}\text { Uji validitas konstruk instrumen } \\
\text { pelaksanaan evaluasi }\end{array}$ & \\
\hline Statistik deskriptif & & $\begin{array}{l}\text { Menghitung mean, persentase } \\
\text { penetapan kriteria dari penelitian }\end{array}$ & \\
& & &
\end{tabular}

Evaluasi Program Sekolah Alam yang dilakukan dengan modifikasi model CIPP skema kerja maupun aspek yang menjadi fokus evaluasi tertuang pada skema sebagai berikut:

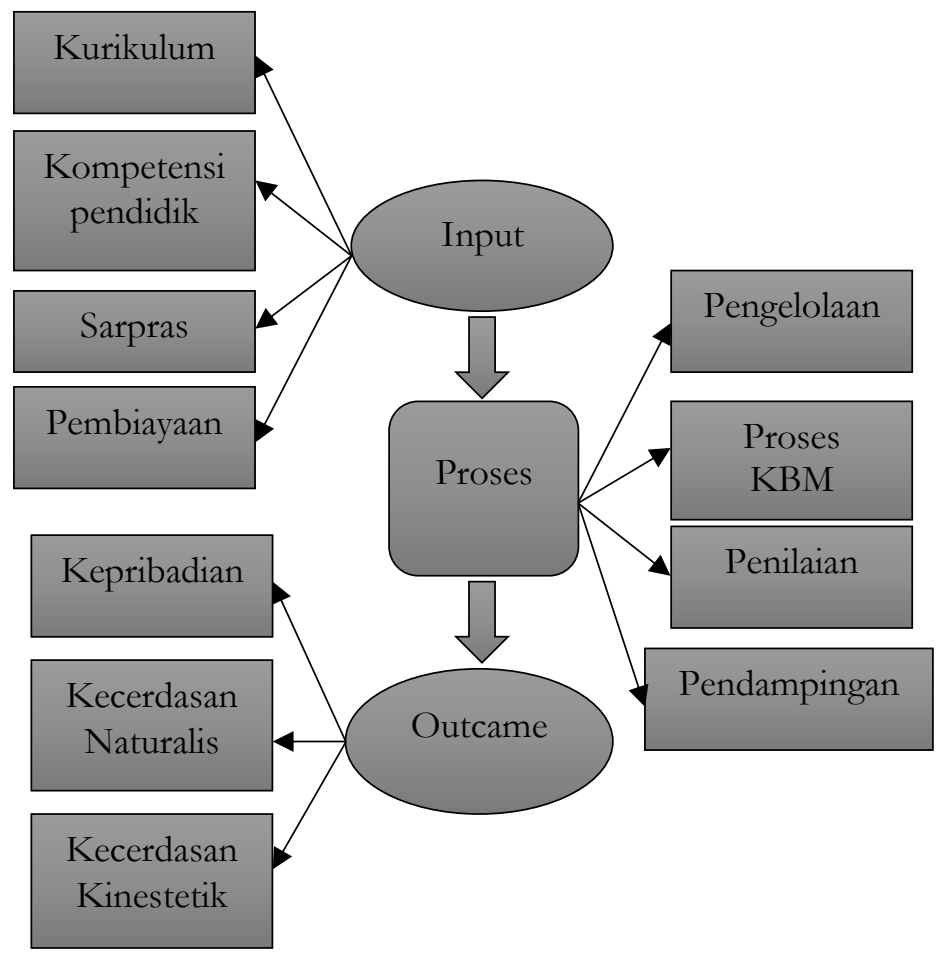


Sekolah Alam: Evaluasi Program Sekolah Dalam Menumbuhkan Kecerdasan Naturalistik Dan Kinestetik Pada Pendidikan Anak Usia Dini

Gambar 1. Pelaksanaan Evaluasi

Evaluasi ini melibatkan 88 responden dengan rincian responden disajikan pada tabel berikut:

Tabel 2. Jumlah subyek Uji coba dan pelaksanaan evaluasi

\begin{tabular}{|l|c|c|}
\hline \multicolumn{1}{|c|}{ Subjek } & Uji Coba & Operasional \\
\hline Kepala sekolah & 1 & 3 \\
\hline Wakil kepala sekolah & 1 & 3 \\
\hline Guru & 4 & 18 \\
\hline Peserta didik & 24 & 58 \\
\hline Maintenance & 1 & 6 \\
\hline Jumlah & 31 & 88 \\
\hline
\end{tabular}

Tabel 3. Subjek Evaluasi

\begin{tabular}{|l|l|}
\hline \multicolumn{1}{|c|}{ Subjek } & \multicolumn{1}{c|}{ Peran } \\
\hline Peserta Didik & $\begin{array}{l}\text { Partisipan pada proses pembelajaran } \\
\text { Sekolah Alam }\end{array}$ \\
\hline Kepala Sekolah, Guru, dan Maintenance & Parameter keberhasilan program \\
\hline & Penyelenggaran Sekolah Alam \\
\hline Pakar Dan Praktisi Evaluasi & Narasumber \\
\hline
\end{tabular}

Kriteria penilaian Sekolah Alam dikatakan baik apabila memenuhi standar yang sudah di tetapkan. Kriteria baik meliputi kesesuaian indikator yang ada pada setiap aspeknya. Berikut adalah kriteria penilaian keberhasilan yang sudah di tetapkan

Tabel 4. Kriteria Penilaian Program

\begin{tabular}{|c|c|c|}
\hline No & Skor & Kategori \\
\hline 1 & $1-1,599$ & Sangat buruk \\
\hline 2 & $1,6-2,199$ & Buruk \\
\hline 3 & $2,2-2,799$ & Cukup \\
\hline 4 & $\mathbf{2 , 8 - 3 , 3 9 9}$ & Baik \\
\hline 5 & $3,4-4,0$ & Sangat baik \\
\hline
\end{tabular}

\section{EVALUASI PROGRAM SEKOLAH ALAM}

Hasil pengukuran dengan Lisrel terhadap hubungan indikator dan variabel laten dalam instrumen berdasarkan data yang diperoleh dari pelaksanaan evaluasi dapat disimpulkan ke dalam tabel sebagai berikut: 
Tabel 5. Goodness Of Fit Instrument

\begin{tabular}{|c|c|c|c|c|}
\hline No & Index & Goodness of Fit & Hasil & Level of Fit \\
\hline 1 & $\begin{array}{c}\text { Chi Square }\left(x^{2}\right) \text { dan Probabilitas } \\
(p)\end{array}$ & $\begin{array}{c}1,27 \\
p=0,15\end{array}$ & Good Fit \\
\hline 2 & $\begin{array}{c}\text { Koot Mean Square Error of } \\
\text { Approximation (RMSEA) }\end{array}$ & $\leq 0,05$ & \\
\hline 3 & NFI (Normed Fit Index) & $\geq 0,90$ & 0,99 & Good Fit \\
\hline 4 & Non Normed Fit Index (NNFI) & $\geq 0,90$ & 0.99 & Good Fit \\
\hline 5 & Comparatif Fit Index (CFI) & $\geq 0,90$ & 0,98 & Good Fit \\
\hline 6 & Incremental Fit Index (IFI) & $\geq 0,90$ & 0,93 & Good Fit \\
\hline 7 & Relative Fit Index (RFI) & $\geq 0,90$ & 0,98 & Good Fit \\
\hline 8 & Goodnees of Fit Index (GFI) & $\geq 0,90$ & 0,92 & Good Fit \\
\hline 9 & $\begin{array}{c}\text { Adjusted Goodness of Fit Index } \\
\text { (AGFI) }\end{array}$ & $\geq 0,90$ & 0,90 & Good Fit \\
\hline
\end{tabular}

(Joreskog, 1993) Nilai $\mathrm{R}^{2}$ dari analisis di atas 1,0 mempunyai arti bahwa keseluruhan indikator dalam instrumen yang dikembangkan dapat merepresentasikan variabel laten (valid). Estimasi model pengukuran juga menunjukkan bahwa setiap indikator instrumen memiliki loading factor yaitu di atas 0,60. Secara keseluruhan interpretasi berdasarkan outcame dengan sembilan parameter yang merupakan kriteria goodness of fit index model (Diamantopoulos, 1994) dalam penelitian terbukti bahwa seluruh parameter memenuhi kriteria goodness of fit index model, sehingga indikator yang dibentuk sudah sesuai dengan variable laten yaitu pelaksanaan evaluasi yang diukur oleh tiga indikator yaitu input, proses dan outcame. Indikator input terdiri dari sub-indikator yaitu kurikulum, kompetensi pendidik, sarpras dan pembiayaan. Pada indikator proses terdiri dari sub-indikator yaitu pengelolaan, proses KBM, penilaian dan pendampingan, dan indikator outcame terdiri dari sub-indikator yaitu kepribadian, kecerdasan naturalis dan kecerdasan kinestetik. Dengan demikian dapat disimpulkan bahwa fit index atau kecocokan model yang diuji adalah baik, artinya indikator dan subindikator yang digunakan pada instrumen dapat menjelaskan variabel pelaksanaan evaluasi Sekolah Alam.

Tabel 6. Hasil Analisis Deskriptif Pelaksanaan Evaluasi

\begin{tabular}{|c|l|c|c|c|}
\hline Aspek & Instrumen Evaluasi & Mean & \% & Kriteria \\
\hline \multirow{4}{*}{ Input } & Kurikulum & 3,315 & 82,88 & Sangat baik \\
\cline { 2 - 5 } & Kompetensi pendidik & 3,420 & 81,52 & Sangat baik \\
\cline { 2 - 5 } & Sarpras & 3,826 & 95,65 & Sangat baik \\
\cline { 2 - 5 } & Pembiayaan & 3,681 & 92,03 & Sangat baik \\
\hline \multirow{3}{*}{ Proses } & Pengelolaan & 3,674 & 91,84 & Sangat baik \\
\cline { 2 - 5 } & Proses KBM & 3,420 & 81,52 & Sangat baik \\
\cline { 2 - 5 } & Penilaian & 3,586 & 89,67 & Sangat baik \\
\hline
\end{tabular}


Sekolah Alam: Evaluasi Program Sekolah Dalam Menumbuhkan Kecerdasan Naturalistik Dan Kinestetik Pada Pendidikan Anak Usia Dini

\begin{tabular}{|c|c|c|c|c|}
\hline & Pendampingan & 3,826 & 95,65 & Sangat baik \\
\hline & Rata-rata & 3,594 & 88,9 & Sangat baik \\
\hline \multirow[t]{4}{*}{ Outcame } & Kepribadian & 3,420 & 81,52 & Sangat baik \\
\hline & Kecerdasan naturalis & 3,674 & 85,50 & Sangat baik \\
\hline & Kecerdasan kinestetik & 3,826 & 95,65 & Sangat baik \\
\hline & Rata-rata & 3,640 & 87,5 & \\
\hline
\end{tabular}

Hasil estimasi reliabilitas uji coba instrumen memiliki nilai $>0,6$. Hasil tersebut dapat disimpulkan bahwa instrumen yang digunakan reliabel. Sementara berdasarkan hasil analisis deskriptif evaluasi pelaksanaan Sekolah Alam pada aspek input dan proses memperoleh skor rerata 3,594 dan 88,9\% yang dapat dikategorikan "sangat baik", sehingga dapat disimpulkan bahwa aspek input yang meliputi kurikulum, kompetensi pendidik, sarpras dan pembiayaan serta aspek proses yaitu pengelolaan, proses KBM, penilaian dan penampingan dapat dikatakan berjalan dengan "sangat baik" sebagai penunjang untuk menghasilkan outcame yang baik. Sebagaimana juga dapat dilihat pada aspek outcame memperoleh skor rerata 3,640 dan 87,5\% yang dapat dikategorikan "sangat baik", dengan demikian dapat disimpulkan bahwa pelaksanaan Sekolah Alam sudah menghasilkan outcame yang sangat baik dalam aspek kepribadian, kecerdasan naturalis dan kecerdasan kinestetik.

\section{KESIMPULAN}

Ada tiga aspek yang dapat menjadi penunjang pelaksanaan Sekolah Alam yaitu input, proses dan produk. Aspek input dapat dilihat dari kurikulum, kompetensi pendidik, sarpras dan pembiayaan serta aspek proses yaitu pengelolaan, proses KBM, penilaian dan penampingan, sementara aspek outcame dapat dilihat dari kepribadian, kecerdasan naturalis dan kecerdasan kinestetik. Hasil evaluasi pelaksanaan menunjukkan bahwa implementasi program yang dapat dilihat dalam aspek input dan proses maupun outcame berada dalam kategori sangat baik, sehingga dapat disimpulkan bahwa kurikulum Sekolah Alam berhasil dilaksanakan.

\section{DAFTAR PUSTAKA}

Armstrong, T. (2009). Multiple intelligences in the classroom (3rd ed). Association for Supervision and Curriculum Development.

Daniati, S. P. (2019). Natural School Culture as a Free And Fun Alternative Education in Building the Students' Character. Elementary Education Online, 18(1). https://doi.org/10.17051/ilkonline.2019.527617

Davis, K., Christodoulou, J., Seider, S., \& Gardner, H. (2010). The Theory of Multiple Intelligences. 37. 
Diamantopoulos, A. (1994). Modelling with LISREL: A guide for the uninitiated. Journal of Marketing Management, 10(1-3), 105-136. https://doi.org/10.1080/0267257X.1994.9964263

Fitriani, R. (2018). Perkembangan Fisik Motorik Anak Usia Dini. 3(1), 10.

Gardner, H. (2011). Frame of Mind: The Theory of Multiple Intelligences (3rd Edition). A Member of the Perseus Books Group, New York.

Hasanah, U. (2016). Pengembangan Kemampuan Fisik Motorik Melalui Permainan Tradisional Bagi Anak Usia Dini. Jurnal Pendidikan Anak, 5, 717-733.

Hashim, H. H., \& Denan, Z. (2015). Importance of Preserving the Natural Environment in the Design Schools in Malaysia. Procedia - Social and Behavioral Sciences, 170, 177-186. https://doi.org/10.1016/j.sbspro.2015.01.027

Joreskog, K. G. (1993). Lisrel 8: Structural Equation Modeling with the SIMPLIS Command Language. Scientific Software International, Inc.

Spalie, N., Utaberta, Abdullah, Tahir, M., \& Ani, C. (2011). Reconstructing Sustainable Outdoor Learning Environment in Malaysia from the Understanding of Natural School Design and Approaches in Indonesia. Procedia - Social and Behavioral Sciences, 15, 3310-3315. https://doi.org/10.1016/j.sbspro.2011.04.291

Stufflebeam, D. L. (2002). Evaluation Models (Second Edition). Kluwer Academic Publishers. http://kluweronline.com

Taylor, A. F., \& Kuo, F. E. (2006). Is contact with nature important for healthy child development? State of the evidence. Dalam C. Spencer \& M. Blades (Ed.), Children and their Environments (hlm. 124-140). Cambridge University Press. https://doi.org/10.1017/CBO9780511521232.009

Widaningsih, T., Widyawati, P. N., Shodiq, A., \& Zayadi, A. (2019). Revolusi Industri 4.0 Dan Pendidikan Aanak Usia Dini Untuk Generasi ALFA: Sebuah Telaah. 2, 9.

Yuningsih, R. (2015). Peningkatan Kecerdasan Kinestetik Melalui Pembelejaran Gerak Dasar Tari Minang. 9, 18. 